\title{
artículos
}

\section{Patrimonio Cultural, el paisaje de la imagen expandida}

\author{
Clotilde Lechuga Jiménez
}

Investigadora vinculada a la Universidad de Granada

\section{RESUMEN}

Tomamos fuentes de la historiografía del arte para documentary analizar la educación de la mirada en occidente, el mensaje transmitido y su repercusión en la sociedad. También se muestra el trabajo de distintos artistas del siglo XX y XXI, que añaden al plano bidimensional la experiencia en el medio ambiente, del recorrido y la noción del tiempo. Finalizamos con un modelo como referente de integración y conocimiento del Patrimonio Cultural y el Patrimonio Natural.

PALABRAS CLAVE: Patrimonio Cultural/ Patrimonio Natural/ Paisaje/Imagen/ Arte.

\section{Cultural Heritage, the landscape of the expanded image}

\section{ABSTRACT}

We study art history sources to document and analyze visual education in West culture, the message and its impact on society. It also shows the work of different artists of the XX and XXI century that add to the two-dimensional surface the environment experience, by walking and by the notion of time. We conclude with a pattern of integration and knowledge of Cultural Heritage and Natural Heritage.

KEY WORDS: Cultural Heritage/ Natural Heritage/ Landscape/ Image/ Art.

INTRODUCCIÓN.

En nuestra idea de la ventana transportable, como elemento visual descontextualizado, es menester tomar conciencia de la educación de la mirada desde occidente, para entender ciertas fuentes gráficas expuestas en dos dimensiones. El uso de ello como objetos comercializados -expresados de forma masiva-, La deshumanización del arte reflexionado por José Ortega y Gasset, y la pérdida del aura en La obra de arte en la época de su reproductibilidad técnica, anunciada por Walter Benjamín, quedan como conceptos lejanos, cuando nos planteamos el distanciamiento crítico que de ello hacemos en el día a día. La accesibilidad a las herramientas de reproducción de lo cotidiano, igualmente, nos genera un hábito en su uso, además de un conocimiento del útil, pero no un planteamiento de cómo, por qué y qué queremos expresar. En otras palabras, es sencillo apretar el botón y copiar y pegar o trasladar imágenes estáticas o en movimiento en una cámara digital, sin pensar el sentido de la imagen o las imágenes que se exponen y la lectura que realizará el

* LECHUGA JIMÉNEZ, Clotilde: "Patrimonio Cultural, el paisaje de la imagen expandida”, en Boletín de Arte $n^{\circ}$ 32-33, Departamento de Historia del Arte, Universidad de Málaga, 2011-2012, págs. 351-361. Fecha de recepción: Junio de 2011. 


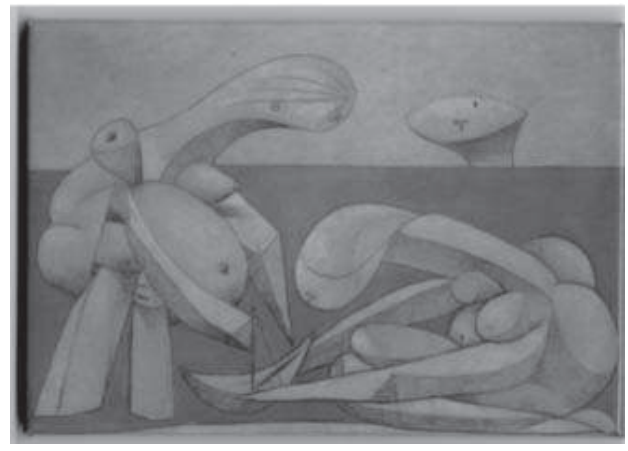

1. Comercialización de la obra de Pablo Picasso, La Baignade (1937).

receptor, algo profundamente inquietante y abierto a interpretaciones. En estos casos, el intermediario/a tiene la responsabilidad de ser cuidadoso o cuidadosa con lo ofrecido.

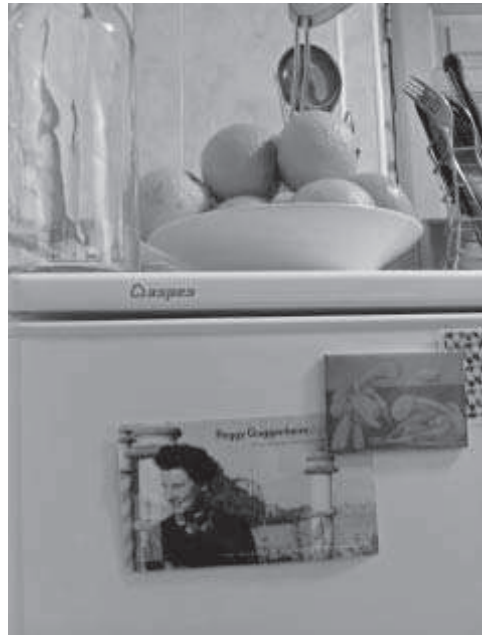

2. (c) Clotilde Lechuga, Peggy y Picasso en Granada (2010).

En este punto, existe una diferencia con

los artistas que sí se plantean la utilización de según qué materias e instrumentos, cuando tienen la voluntad y la $<<$ necesidad $>>$ de comunicar una inquietud, mostrar una vivencia o compartir un conocimiento. De hecho, esa actitud y pensamiento crítico debemos defenderlo al formar parte de una sociedad que tiene que dejar de ser paternalista para concienciarnos de nuestra mayoría de edad y expresarnos como civiles artistas, creadores, usuarios o teóricos, entre otros sectores. La <<ventana transportable>>, que nos refiere la imagen del objeto en el suporte bidimensional, nos permite la apropiación de la obra de arte, como hemos sugerido con los imanes del Museo Peggy Guggenheim Collection de Venecia, en los que se reproduce el objeto pictórico de alguno de los artistas, perteneciente a su colección privada. En el reverso del imán aparecen los datos de identificación. La siguiente ilustración muestra la reproducción del cuadro de Pablo Picasso, el cual, de este modo tan simple, pasa a formar parte de nuestro inventario doméstico a escala reducida, decorando, por ejemplo, electrodomésticos como el refrigerador de la cocina, y si se desea, con una funcionalidad sosteniendo anotaciones u otros souvenirs. La "apropiación" entra en el territorio privado de nuestro entorno cotidiano. [1 y 2]

La puesta en valor del patrimonio visual-claramente cultural en lo que exponemos aquí- es una labor desarrollada fundamentalmente a partir de la segunda mitad del siglo $\mathrm{XX}$, tras la destructora guerra mundial europea, cuando las reconstrucciones de las ciudades y espacios monumentales toman la importancia de la geografía del propio cuerpo humano. Recuperar la solidez de lo destruido es dar visualidad a la 
reconstrucción de la masacre personal y social. También surge una conciencia del espacio. El propósito es contextualizar la obra integrada en el Patrimonio Natural, del que sin duda formamos parte, refrescándonos la mirada con paisajes conocidos, que han ido reinventándose, en muchas ocasiones a nuestro capricho, y por ello componen nuestro legado paisajístico, como una identidad más, dentro del concepto desarrollado al que denominamos patrimonio cultural.

\section{Materiales y metodología.}

\section{La imAgen Sin PERSPectiva.}

Nuestra propuesta para entender y difundir el concepto patrimonial es la de contrastar distintos elementos que consideramos dentro del apartado de uso social, cultural y de ocio. La metodología utilizada es la enunciación de elementos y la comparación de éstos, a partir de los cuales reflexionamos sobre las posibilidades que tienen los mensajes de evolucionar en su comprensión y aceptación. De ello surge la intención de realizar un estudio abierto a nuevas aportaciones materiales y metodológicas, con anexos que permitan desarrollar una información no codificada, receptiva a distintas valoraciones y autores.

Tomamos estas palabras de Jesús Rubio, que nos parecen interesantes como premisas en este artículo para describir dos funciones del arte, que podemos aplicar a las imágenes expandidas en superficies planas, como son los soportes en papel o en las pantallas de los ordenadores, la televisión o el cine.

"El arte interviene con una función integradora, organizativa que se lleva a cabo a partir de la representación. Esta organización del arte para con la naturaleza tiene dos líneas básicas que reflejan la doble significación del término naturaleza. Una objetiva encaminada a la representación de lo empírico y contingente, y otra más subjetiva que tiende más hacia lo interior, lo oculto e irracional, en la que lo metafísico es habitualmente integrado."1

El arte, en la representación bidimensional gráfica, abarca esas dos líneas de doble significación: una de contenido científico, basada en la captación del hecho o del dato, y otra, en la que la subjetividad, tanto del autor/a como del receptor/a, es la propuesta en sí. En estas variantes nos encontramos cuando iniciamos el proceso de captación del espacio desde las vistas aéreas. La propuesta que en el segundo futurismo italiano de 1929 Marinetti da a conocer con el Manifiesto de la Aeropintura

1 RUBIO LAPAZ, Jesús: "La Poética de Aristóteles y su vigencia en el arte contemporáneo", en ALVAREZ MORAN, M. C. y IGLESIAS MONTIEL, R. M. (coord.): Contemporaneidad de los clásicos en el umbral del tercer milenio: actas del congreso internacional de los clásicos. La tradición grecolatina ante el siglo XXI. La Habana (Cuba), 1999, págs. 441-446. 


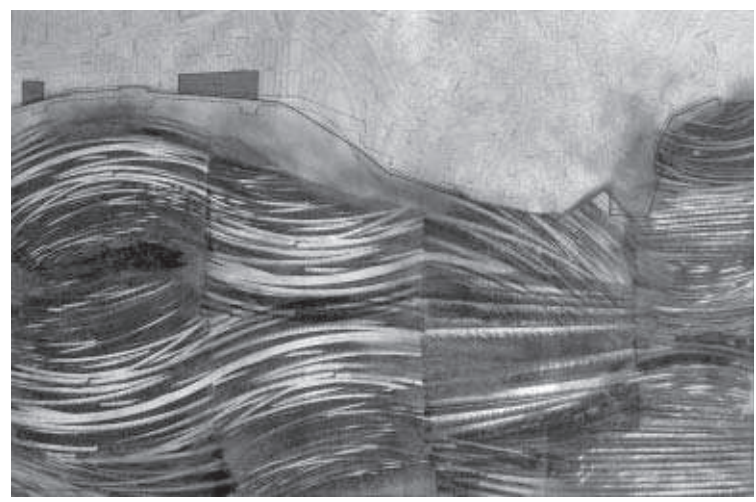

está representada con importancia por la obra de Prampolini, basada en la acción de pintar desde las alturas -desde un aeroplano- y en movimiento -mientras éste se desplaza -, constituyendo el acto de mayor modernidad al obtener distintas visiones desde un punto de vista poco cotidiano, y más en ese momento del primer tercio del siglo XX. El movimiento que queda representado en una visión estática constituye otro apartado de estudio. La intención de la mirada cenital de representar el mundo con mayor amplitud de lo que se ve, sin elementos que nos interrumpan el encuadre debido a que no hay puntos de fuga lineales, -al carecer de perspectiva pues el fondo del paisaje es el soporte terráqueo- es totalmente distinta a la desarrollada por la metodología empírica del Renacimiento Italiano, la cual aportaba continuados datos de los distintos estudios científicos, que se elaboraban sobre el objeto en el espacio, la variación de la luz en su proyección y la variabilidad de su visión según el distanciamiento medido y representado en papel, para su futura representación en cualquier otro soporte. La vista de pájaro se choca contra la pared de la tierra. Los azules de los mares y de los ríos no tienen posibilidad de horizonte. El mismo color en la representación del cielo permite la idea de profundidad conocida por nuestra mirada, pues sabemos que existe un fondo, normalmente compuesto por un territorio conocido, aunque en ocasiones sean descripciones completamente ajenas a nuestro entorno paisajístico. En cambio, la materialidad del agua tan sólo permite reflejos de un universo plano geométricamente, ésto es, donde el haz de luz es siempre una línea recta. Es literalmente un espejo. Una superficie que emite el reflejo de la imagen bidimensional ${ }^{2}$. [3]

2 Es justo mencionar las intenciones de la artista plástica Charo Carrera con su obra, por lo que a continuación insertamos sus palabras en una nota de 2010, las cuales tienen un claro compromiso con las redes de inter/ trans- actuación de la denominada biodiversidad o co-evolución,

"Con estas obras estoy estudiando la intervención que el hombre hace en la naturaleza, bien sea a través de terrenos cultivados, montañas aprovechadas para formar salinas o terrazas de arroz u otros cultivos, así como la estructuración del núcleo habitable. Caminos que empiezan y que se cruzan, construcciones que forman nuestra casa, nuestra ciudad; labores de campo que conforman una red, un sistema reticular que se repite también y que se encuentra en todos los organismos, ya sean vegetales, animales o minerales." 
4. Leonardo da Vinci, Paisaje a vista de pájaro (1502).

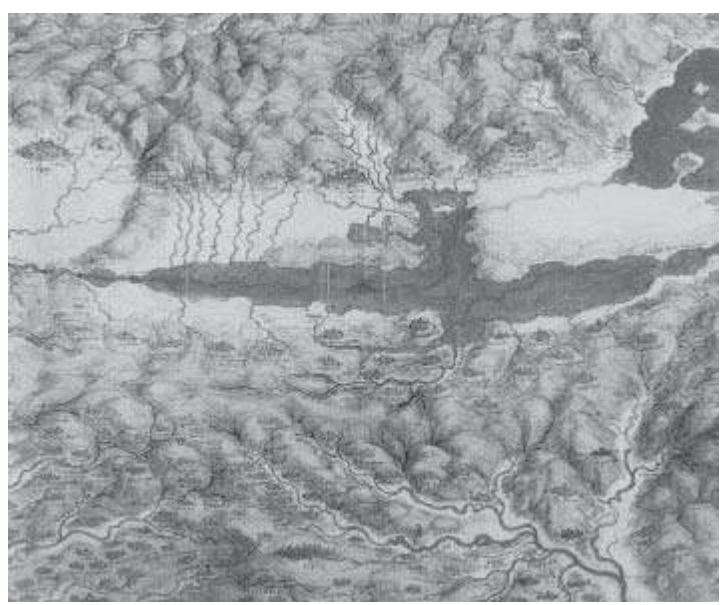

Son admirables - mirar con distancia/acción de mirar- los paisajes a vista de pájaro que en 1502 realizó Leonardo da Vinci -cuando fue contratado como ingeniero militar al servicio del general César Borgia-, en las que registra con dibujos la descripción topográfica de la zona central de Italia ${ }^{3}$. [4]

La abstracción de la mirada aérea inventada, para que el espectador entienda la geografía y la topografía del territorio, parece algo extraordinario por la claridad expositiva y comunicativa de esta ilustración, si no supiéramos que estamos ante un trabajo llevado a cabo por Leonardo, el mismo genio que en la segunda mitad del siglo $\mathrm{XV}$, mide los objetos en el espacio e investiga el efecto de la mirada sobre un plano tridimensional geométrico -volumen- y sobre una superficie plana bidimensional, participando y enriqueciendo -en el sentido más creativo- la búsqueda de la interpretación de la perspectiva, aplicando una metodología científica basada en el dato y su traslación al soporte papel, en relación con el estudio de la percepción visual humana ${ }^{4}$.

Algunos de los planos realizados con ahínco en Europa, desde finales del siglo $\mathrm{XV}$, fueron elaborados por topógrafos e ilustradores, con un cometido funcional para el sector militar. En lo referente a la tipología de imágenes corográficas, la descripción es una vista cenital sobre la ciudad. Está claro que para elaborar el mapa de la Ciudad de Imola (c. 1504), el artista utilizó "un astrolabio o un instrumento muy parecido para obtener las medidas de sus mapas", "una brújula de la rosa de los vientos" y "contaron

3 ZÖLLNER, Frank: LEONARDO DA VINCI (1452-1519). Köln, Taschen, 2004, p. 67.

4 En el libro del profesor KEMP, Martin: La ciencia del arte. La óptica en el arte occidental de Brunelleschi a Seurat. Madrid, AKAL, 2000 se expone, de forma detallada, los distintos estudios de los diferentes planos que nos ofrece el espacio y la reinterpretación llevada a cabo por la Historia del Arte, en la cultura occidental, desde el Renacimiento Italiano. 


\begin{tabular}{|c|c|}
\hline 拝 artículos & Clotilde Lechuga Jiménez \\
\hline
\end{tabular}

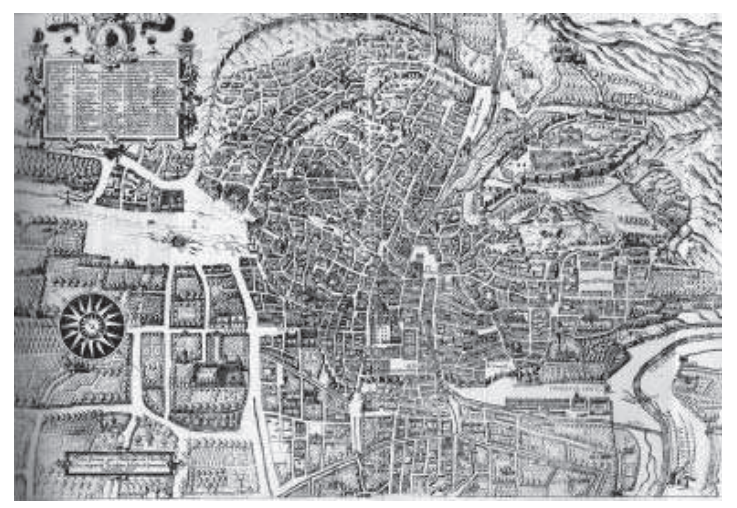

5. Ambrosio de Vico,
Platafoma de Granada
(1613).

a pasos él y sus ayudantes" ${ }^{\prime \prime}$. Vemos que aproximadamente un siglo más tarde se realizan planos similares como el de la ciudad de Granada, a principios del siglo XVII, realizado por el arquitecto Ambrosio de Vico. [5]

Lo que nos muestran estos documentos son una información científica desde una mirada ficticia, desde la idea de que el ojo humano, por sí sólo, es incapaz de encuadrar con la vista espacios tan amplios de la superficie terráquea a la vez, ni tan esquematizados, por lo que es evidente que nos encontramos ante interpretaciones de áreas y de su trazado urbano.

En el siglo XXI, la certeza técnica mostrada por la fotografía satélite nos muestra la imagen realizada por una máquina desde el aire, a muchos kilómetros de distancia. La fotografía llega a ser la culminación de los estudios sobre la plasmación del objeto en dos dimensiones y los estudios sobre perspectiva comenzada en el Renacimiento Italiano. El avance de ésta y sus captaciones fidedignas es algo que nadie pone en duda, aunque se nos ofrezca imágenes imposibles de visualizar por el ojo humano de modo natural, sin la utilización de herramientas que nos acerquen el objeto o la zona encuadrada. Google Earth ha revolucionado el sistema de mapas y vistas aéreas, consiguiendo estar en el mercado on line gratuito, como un accesorio útil. Ha creado la necesidad en la sociedad actual, ofrece su servicio y es consumida cada vez más por los usuarios de todo el mundo. Nuestra capacidad lectora entiende perfectamente el lenguaje de la descripción de unas imágenes, que de nuevo son imposibles de captar en su totalidad por las limitaciones físicas del ser humano, pero sí lo son por lentes. (Nosotros las podemos ver fragmentadas y reunir en nuestra memoria). Todas estas vistas carecen de perspectiva y verosimilitud en cuanto a la posibilidad óptica antropológica. [6]

5 Ibidem, p. 183. 


\begin{tabular}{|c|c|c|}
\hline 啡車 & articulos & Patrimonio Cultural, el paisaje de la imagen expandida \\
\hline
\end{tabular}

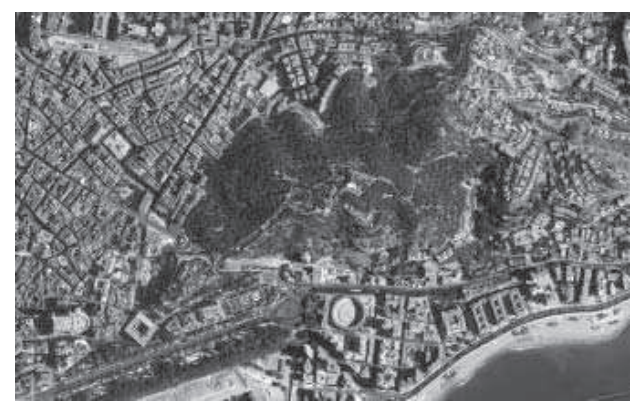

6. (c) Google Earth, Málaga (2010).

7. (C) Jackson Pollock, Echo (Number 25) (1951).

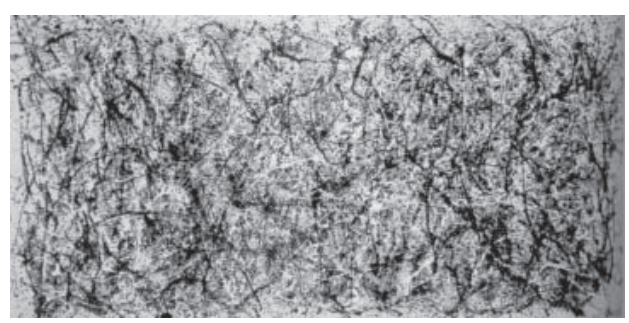

Contrastando con el arte objetivo -imaginativo- y empírico de la técnica fotográfica tenemos el arte subjetivo del expresionismo abstracto de Jackson Pollock, también sin referente de perspectiva lineal, ni atmosférica, sin ningún signo de profundidad. La técnica del drip paintings que utiliza la fuerza de la gravedad de la Tierra, para hacer caer el fluido pigmentado, se encuentra con la imposibilidad de transgredir esa pared que es el suelo con la materia, pero sí con la mente, al crear una atmósfera envolvente. Las cinco obras expuestas en este punto poseen denominadores comunes: las miradas cenitales, la necesidad de reinterpretarlas tras la interpretación primera del autor/a o máquina y la falta de perspectiva. [7]

\section{El objeto contextualizado.}

Los grabados publicados por Goerg Braun y Franz Hogenberg, en Colonia, para ilustrar Civitates Orbis Terrarum "voluminosa obra de seis volúmenes, que vieron la luz entre 1572 y 1617, con 363 láminas que representan a 531 poblaciones”“ es una muestra del interés, que en este sentido, se tenía hacia las vistas corográficas. En este caso, Vistas que se pudieran confundir con el término paisaje, pues están próximos en su apreciación del territorio o país.

6 CAMACHO MARTİNEZ; Rosario: "Apuntes sobre la planimetría de Málaga. Para una lectura de la ciudad en la Edad Moderna”. En: Las ciudades históricas del Mediterráneo. Fuentes literarias y representación gráfica. Del Mundo Antiguo a la Edad Contemporánea. ASENJO RUBIO, Eduardo y CAMACHO MARTíNEZ, Rosario (edit.). Málaga, Universidad, Dpto. Historia del Arte, 2008, p. 102. 


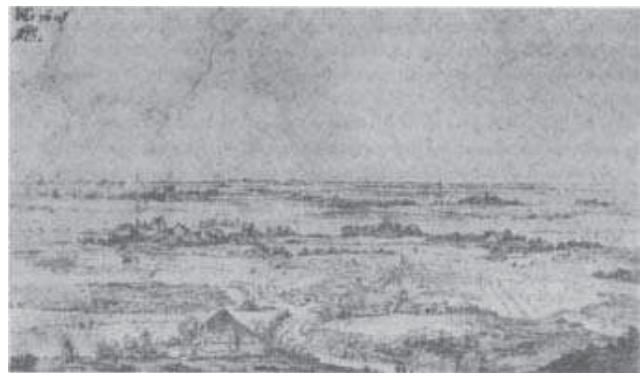

8. Hendrick Goltzius, Paisaje de dunas cerca de Haarlem (h. 1603). Dibujo.

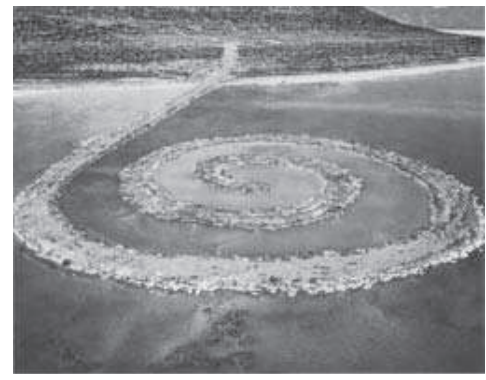

9. (C) Robert Smithson, Muelle en espiral (1970).

Durante siglos, en la cultura occidental, la emancipación del término <<paisaje >> ha correspondido a una independencia dentro de la disciplina de la pintura, contribuyendo a la construcción de este término con otro sentido diferente al que originariamente se tenía de <<país>>. Según escribe Javier Maderuelo ${ }^{7}$, fueron los pintores holandeses, de principios del siglo XVII, los que incluyen el término (landtshap) en la disciplina de la pintura de forma autónoma y, por tanto, su correspondiente concepto de territorio aislado, encuadrado y descontextualizado. [8]

La representación del paisaje y sus cambios de valor se han ido modificando durante siglos en la cultura occidental, con ejemplos como las dos vistas Vista de Toledo (ca. 1600) y Vista y plano de Toledo (ca. 1610) ${ }^{8}$ pintadas por El Greco sobre la ciudad de Toledo $^{9}$, en las cuales se describe la ciudad, con sus edificios ilustres y la muralla que la circunda, o la poderosa presencia de la Naturaleza que le adjudicaron los románticos, como podemos apreciar en la trayectoria de Caspar David Friedrich, con algunas de sus obras como el célebre cuadro de El caminante frente al mar de niebla (h. 1818). Pero nos queremos centrar en el siglo XX y XXI, en el que la conciencia ecologista se declara como protectora medioambiental. Según Javier Hernando podríamos datar su origen o surgimiento en 1971, con un hecho concreto, "un grupo de canadienses a bordo de un viejo barco llamado Phillys Cormak intentaron oponerse al desarrollo de las pruebas nucleares realizadas en la isla de Amchitka, situada en el Pacífico norte. Sería el fermento para la constitución de Greenpeace." ${ }^{10}$. Las manifestaciones artísticas

7 MADERUELO, Javier: El paisaje. Génesis de un concepto. Madrid, Abada, 2005.

8 El estudio de esta Vista es de mayor complejidad, requiriendo la aproximación a ella como estudio sobre $<<$ iconografía >> añadido al de la <<mirada >> que realizamos.

9 Para Javier Maderuelo este cuadro no representa una vista topográfica ni una pintura emblemática, debido a que reúne una vista desde el norte de la ciudad y otra desde el sur creando una "contradicción de dos vistas". Además el autor piensa que este cuadro -y otros dos más de vistas de Toledo que estaban en su taller, tras su muerte- pudieran haber sido utilizados como modelo de paisaje de fondo, pasando a considerarse "paisaje autónomo". Opus cit. MADERUELO, Javier. El paisaje..., p. 314.

10 HERNANDO, Javier: "Visiones de la naturaleza: el arte y la sensibilidad ecológica". En: Tendencias del arte 
en los parajes naturales como las actuaciones del Land Art un año antes, nos indica que la motivación estaba iniciada, como aparece en la obra de Robert Smithson, en la que deja a la Naturaleza que se exprese en su medio, tras haber sido intervenida por la mano del ser humano. [9]

Aunque en 1995, la obra de Richard Long propusiera algo más que las dos dimensiones en las que quedan registradas las imágenes que estamos mostrando. La lectura del texto bajo el cuadrado que representa el azul del cielo, en el que hay cabida para múltiples universos, nos añade la medida con cronómetro del tiempo, la cuarta dimensión: un recorrido de tres días medio caminando, desde la desembocadura del río Loira (Francia) hasta la primera nube. [10]

La escultura y la arquitectura tienen su lugar en la realidad tridimensional, constituyendo un volumen al que estamos obligados a rodear, para apreciar el mensaje que quiere ser transmitido, como exponen Richard Long en lo referido al Patrimonio Natural o Richard Serra en el Patrimonio Cultural. La reproducción mecánica difundida en libros, postales u otros soportes, según el texto Sobre la fotografía de Walter Benjamin ${ }^{11}$, es una herramienta que nos permite disfrutar la obra de arte al poderla dominar con la mirada y como objeto- en dimensiones minimizadas. Actualmente, la difusión en la red es lo que nos facilita ese poder de llegar a, prácticamente, todos los lados, sin salir de casa, como ocurría con la cartografía decorativa holandesa del siglo XVI. Utilizamos la pantalla del ordenador para navegar por internet y recorrer distintas ofertas internacionales. En muchas ocasiones, la imagen mostrada, aislada y encuadrada, nos atrae y nos seduce para ir al lugar y posteriormente, in situ, nos quedemos admirando la misma <<ventana transportable>> ofrecida por los medios. Imágenes que buscamos para reproducirlas como vivencia y certificación de su existencia. Nuestro deseo es interactuar en ese espacio y tener otras experiencias. El acercamiento al objeto se presenta primero desde el plano visual, empequeñeciéndolo en la mayoría de las ocasiones, para despertarnos la necesidad de visitarlo. Richard Serra nos hace caminar y experimentar la sensación del espacio, interactuando en el recorrido, el tiempo, el entorno donde se encuentra su escultura y con nuestra dimensión corpórea. [11]

de tendencias a principios del siglo XXI. Madrid, Ensayos Arte Cátedra, 2004, p. 56

11 BENJAMIN, Walter: Sobre la fotografía. Valencia, PRE-TEXTOS, 2004. 


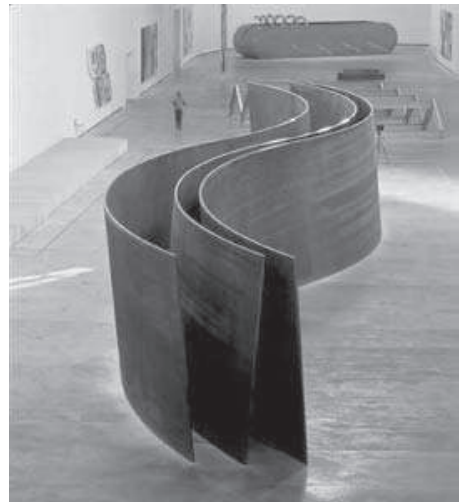

11. (c) Richard Serra, Serpiente. Museo Guggenheim. Bilbao.

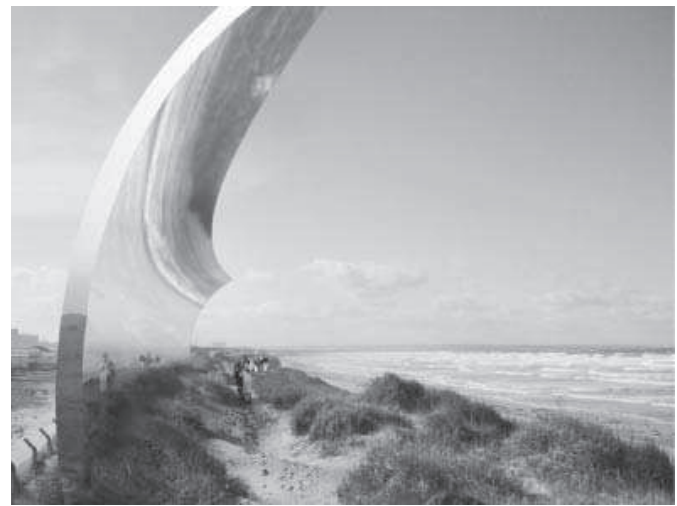

12. (c) Anish Kapoor. See Mirror (2006).

El artista Anish Kapoor aquí juega con la imagen del Patrimonio Natural, en la naturaleza y con la reflexión de ésta, al exponer un espejo gigante cóncavo en una playa. En él los paseantes se pueden ver reflejados, incluidos en el paisaje, formando parte activa de la obra expuesta. En una entrevista, en 1998, colgada en su página web, nos explica la misión o responsabilidad que siente que tiene como artista,

"Is it my role as an artist to say something, to express, to be expressive? I think it's my role as an artist to bring to expression, it's not my role to be expressive. I've got nothing particular to say, I don't have any message to give anyone. But it is my role to bring to expression, let's say, to define means that allow phenomenological and other perceptions which one might use, one might work with, and then move towards a poetic existence." ${ }^{12}$ [12]

En la actualidad se están ampliando las posibilidades de disfrutar del Patrimonio Cultural y del Patrimonio Natural de manera conjunta con los estudios desde distintas disciplinas. Un modelo que contiene elementos citados en este articulo en el uso patrimonial y la difusión de la imagen es el realizado por el Patronato de La Alhambra y el Generalife. Los monumentos y sitios arqueológicos se contextualizan en su entorno natural. "Al adscribirse en 1921 los Jardines del Generalife se amplía el concepto y el territorio. Hay que considerar que los cambios que suceden durante siglos en la

12 http://www.anishkapoor.com/ [Consultado 29/11/2010]. De las conversaciones entre Anish Kapoor y Homi K. Bhabha. Traducción libre del inglés al español de la autora: “ ¿Es mi función como artista decir algo, expresar o ser expresivo? Creo que mi función como artista es llevar hacia la expresión, pero no ser expresivo. No tengo nada especial que decir, no tengo ningún mensaje que dar a nadie. Pero es mi función llevar hacia la expresión, ésto es, definir significados que permitan a las percepciones (tales como la fenomenológica y otras), con las que podemos trabajar y usar/utilizar, para así movernos entorno a una existencia poética.". 


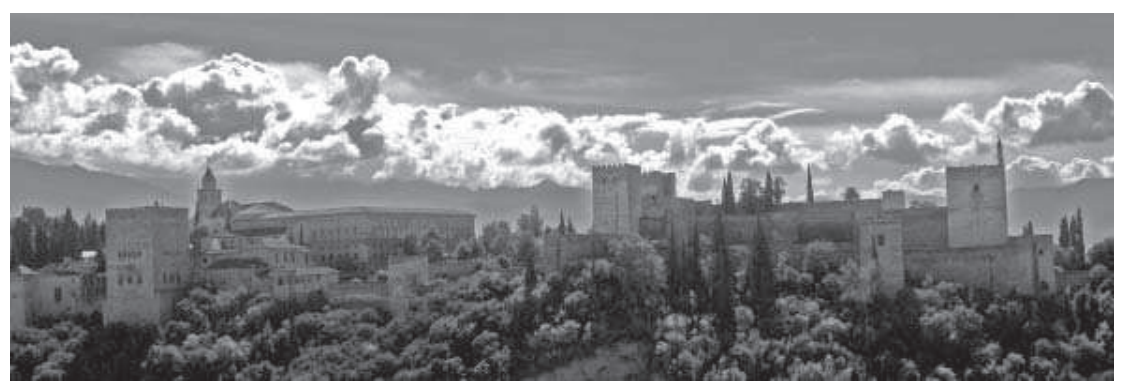

13. (C) Clotilde Lechuga, Recordando Granada (2010).

colina Sabika van consolidando el paisaje que tenemos de ella."13. El <<paisaje>> construido por el hombre cobra mayor sentido al entender la formación de la topografía que define el lugar a través de su geología. El Territorio Alhambra ${ }^{14}$ se expande fuera de las murallas del conjunto histórico, constituyendo un referente con la aportación de datos investigados por científicos y técnicos. Intramuros y extramuros se ofrece la opción de disfrutar y comprender directrices nuevas en el campo de la expresión artística -historicista y actual al apostar por el trabajo de artistas que contribuyan a la innovación en la mirada del sitio, las emociones y experiencias que se descubren-. La imagen expandida del lugar es sólo un avance del disfrute del legado patrimonial. Es un anzuelo visual para que culmine en una experiencia en el aprendizaje. [13]

\section{Debate y conclusión.}

La intención artística como interpretación de la realidad en su espacio, cambia continuadamente entre lo subjetivo y lo objetivo, entre la creación y la documentación. Se trata de un binomio que evoluciona como concepto y como herramienta, a través de la Historia del Arte, la Historia de la Humanidad y la Historia de la Mirada.

13 LECHUGA JIMÉNEZ, Clotilde: “Paisaje Cultural y Patrimonio Visual: Granada y Málaga”. En: IV Seminario Internacional CULTURA Y COOPERACIÖN: Formación y capacitación en Patrimonio como alternativa de desarrollo sostenible. Granada, 2010. Restauradores Sin Fronteras www.a-rsf.org , 2010, p. 41.

14 En 2010 se publicó el Plan Director de La Alhambra 2007-2015 - galardonado con el premio Europa Nostra en noviembre de 2010- en donde se detalla las investigaciones y actuaciones que ofrece el Monumento inscrito en la lista de Patrimonio Mundial por la UNESCO. Para más información se puede consultar su página de difusión en la red www.alhambra-patronato.es/ [Consultado 18/5/2011]. 
